к.э.н, старший научный сотрудник Џентра постсоветских исследований ФБГБУН «Институт экономики» $\rho A H$, e-mail: redknight@bk.ru

\title{
DOI:10.26726/1812-7096-2021-2-91-98 \\ ПЕРСПЕКТИВЫ ЭКОНОМИЧЕСКОЙ ИНТЕГРАЦИИ АБХАЗИИ И РОССИИ
}

Аннотауия. Џель работы: целями данной статьи являются исследование экономики Абхазии после признания независимости, обзор формирования экономических отношений

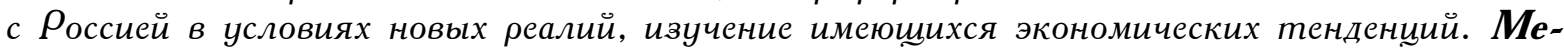
тод или методология проведения работы: проводится сравнение экономики до и после признания независимости, анализируются торговые отношения, структура импорта и экспорта за последние годы. Выявляются сущеествующие закономерности в развитии, перспективы развития и сотрудничества в разных сферах, а также озвучиваются существующие проблемы. Область применения результатов: результаты исследования важ-

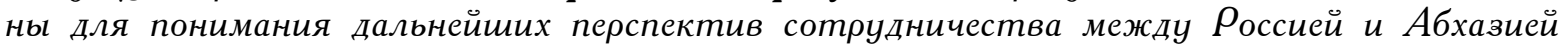
на государственном уровне, а также полезны для бизнеса и инвесторов. Выводы. На основании всего вышеизложенного сделаны выводы, отражающие позицию автора и его понимание текущей ситуации. Названы ключевые проблемы, определены возможные варианты их решения, а также обозначены перспективы дальнейшего развития.

Ключевые слова: Абхазия, Россия, экономика, импорт, экспорт, развитие, перспективы, инвестиции.

SIPARO KONSTANTIN ALEKSEEVICH

Ph. D. in Economics, Senior Researcher, Center for $\rho_{\text {ost-Soviet Studies, }}$ Institute of Economics, Russian Academy of Sciences, e-mail:redknight@bk.ru

\section{PROSPECTS FOR ECONOMIC INTEGRATION OF ABKHAZIA AND RUSSIA}

Abstract. The purpose of this article is to study the economy of Abkhazia after the recognition of independence, to review the formation of economic relations with Russia in the context of new realities, to study the existing economic trends. The method or methodology of the work: the comparison of the economy before and after the recognition of independence, the analysis of trade relations, the structure of imports and exports in recent years. The existing patterns in development, prospects for development and cooperation in various fields are identified, as well as existing problems are voiced. Scope of the results: the results of the study are important for understanding the future prospects of cooperation between Russia and Abkhazia at the state level, as well as useful for business and investors. Conclusions. Based on all of the above, conclusions are drawn that reflect the author's position and his understanding of the current situation. The key problems are identified, possible solutions are identified, and prospects for further development are outlined. Keywords: Abkhazia, Russia, economy, import, export, development, prospects, investment.

\section{Перспективы экономической интеграции Абхазии и России}

Введение. В СССР Абхазия была аграрной зоной с развитым табаководством, чаеводством, цитрусоводством, развитым зерновым хозяйством и животноводством. Большую роль в экономике играло курортное хозяйство и туризм.

После событий 2008 года и признания независимости республики Россия начала оказывать регулярную финансовую помощь, направляемую на восстановление инфраструктуры и социальных объектов, стимулируя развитие экономики. Начал увеличиваться туристический 
поток в республику, состоящий преимущественно из граждан России. При поддержке государства модернизируется агропромышленный комплекс, в совокупности с туризмом ставшим направляющим вектором развития экономики Абхазии.

С Российской Федерацией был подписан ряд договоров и соглашений о помощи и сотрудничестве. Создана «Инвестиционная программа содействия социально-экономическому развитию Республики Абхазия» сроком на три года, куда в первую очередь были включены социальные объекты и инфраструктуры, а затем и объекты реального сектора экономики [10].

Пришедший к власти в мае 2014 года президент Рауль Джумкович Хаджимба назвал в числе своих приоритетов объединение народа и дальнейшее развитие отношений с Россией, нацеленное на сотрудничество в ряде направлений, включая охрану границ, оборонную сферу, экономику. В 2015 году он поставил перед государством задачу увеличения собственных доходов бюджета, достигнув в два раза более высоких показателей в 2016 году благодаря повышению эффективности управления налоговыми и таможенными секторами [12].

Во время его правления главным внешним политическим и экономическим партнером страны осталась Россия.

С 23 апреля 2020 года президентом стал Аслан Бжания.

\section{Методы \\ Экономика}

Абхазия прилагает немалые усилия для развития предлагаемых туристических услуг. Стране есть что предложить, это подтверждается увеличивающимся каждый год количеством прибывающих сюда на отдых, хотя конкурировать в глобальных масштабах и непросто. В 2014 году страну посетило около 700 тыс. человек, а в 2019 году - более одного миллиона.

В 2016 году Абхазия приняла программу развития туризма, которая стала одним из столпов развития экономики республики. Была организована перепись объектов историко-культурного наследия, содержащая данные о 2,5 тыс. объектах, которая дала толчок развитию геоинформационной системы.

Что касается торговых отношений, то Россия является основным импортером абхазской продукции, причем за период с 2014 по 2019 год количество ввозимых товаров выросло в два раза. Абхазия вошла в пятерку поставщиков винодельческой продукции на российский рынок.

За последние 5 лет также увеличилось количество экспорто ориентированных предприятий. Благодаря поддержке ООО «Инвестиционное агентство» появилось восемь проектов общим объемом инвестиций, превышающим миллиард рублей. Данные проекты включают предприятия по выращиванию и переработке фруктов и овощей, хлебобулочных и макаронных изделий, мясоперерабатывающий завод, гостиничные комплексы. Результатами реализации данной программы являются создание 450 рабочих мест и налоговые поступления в размере 160 миллионов рублей в год.

На территории Абхазии уже несколько лет функционирует Государственное инвестиционное агентство, ставящее целью поддержание инвесторов. Данная структура успешно курирует более десяти крупных инвестиционных проектов по всей Абхазии.

Согласно закону об инвестиционной деятельности, крупным инвесторам предоставляется ряд преференций и послаблений. Инвестпроекты, признанные соответствующими определенным требованиям, освобождают от налога на прибыль и налога на имущество. Подобные налоговые каникулы могут быть предоставлены государством не более чем на восемь лет. Действующая программа поддержки экспорто ориентированных организаций предусматривает оказание финансовой помощи и на возмещение предприятиям затрат, сопряженных с производством и распространением продукции.

Существует программа поддержки, нацеленная на реконструкцию и модернизацию объектов социальной сферы и инфраструктуры. Большая часть фондов идет также и на восстановление энергетического хозяйства республики, находящегося в плохом состоянии. В программу также входит финансирование объектов реального сектора экономики сельскохозяйственной направленности.

Однако нужно упомянуть и некоторые негативные моменты. Уровень жизни населения республики пока неудовлетворителен, находясь значительно ниже показателей России, а ВВП на душу населения ниже в четыре раза. Согласно данным Центра стратегических исследова- 
ний при президенте Абхазии об анализе состояния экономики республики, за последнее десятилетие снизилось собственное производство в республике, уменьшилось количество занятого населения, выросла доля теневой экономики страны и упал ВВП страны.

Экономика Абхазии почти ничего не производит, уменьшаются объемы собственного производства и растет доля импорта. За прошедшие 5 лет импорт в Абхазии увеличился более чем на 12 миллиардов рублей, а экспорт всего на 4 миллиарда.

За прошедшее десятилетие уменьшилось с 9 до 7 тыс. кубометров производство пиломатериалов, извести - с 130 до 18 тонн, хлебобулочных изделий - с 6 тысяч до 3,7 тыс. тонн. Прирост показателей наблюдается в производстве вина, пива и минеральных вод, что связано с развитым экспортом и созданными для развития данного направления условиями.

Количество занятого населения за последние пять лет также сократилось. Из 140 тысяч трудоспособных лиц официально работают лишь 50 тысяч. Ежегодно на рынке труда Абхазии трудоустраиваются примерно только 460 человек, наблюдается снижение заинтересованности и вовлеченности в сферы строительства и торговли [1].

Теневая экономика составляет более 50 \% от ВВП Абхазии, что составляет свыше 15 миллиардов рублей, с 2016 года расходы населения начали превышать доходы.

За последние пять лет ВВП в номинальном выражении увеличивается в среднем на 5 \% в год, в то время как инфляция составляет $10 \%$. Доля государственного сектора - $15 \%$, в то время как среднемировые показатели - около $30 \%$, при том что в госсекторе республики заняты 75 \% от общей численности работающих.

Основным источником собственных доходов Абхазии является налог на прибыль и добавленную стоимость, приносящий в казну примерно три миллиарда рублей. Однако эта же сумма уходит на поддержку общегосударственных направлений, национальной безопасности и правоохранительной деятельности, а финансирование социальной политики в 2018-2019 годах составило только 260 миллионов. Эта сумма составляет лишь $3 \%$ от бюджета, в то время как в России это значение близко к $30 \%$.

Объем инвестиций в Абхазию за последние 5 лет составил около 22 миллиардов рублей. Благодаря этой сумме было создано более 2200 рабочих мест, ВВП вырос на 4,5 миллиарда рублей. Но инвестиции не стали двигателем развития экономики. В предыдущие 5 лет инвестиций было меньше - 18,5 миллиарда, а результат был значительно лучше - численность занятых увеличилась на пять тысяч человек, а ВВП - на 9 миллиардов рублей.

Увеличившаяся сумма инвестиций ухудшила отраслевую структуру ВВП. В 2014-2015 годах на первых местах находились строительство и торговля, совместно формируя почти половину ВВП, а сейчас 40 \% ВВП формирует торговля.

Без изменений в последние пять лет осталась численность населения Абхазии. Согласно данным Управления государственной статистики, в 2014-2019 годы прирост населения составил $1,02 \%$, поднявшись с 242 тыс. 756 человек до 245 тыс. 246 человек.

С 2014 по 2019 год ВВП республики увеличился примерно на 20 \%: с 27 млрд руб. до 33 млрд руб. (официальной валютой Абхазии является российский рубль). Среднемесячный прожиточный минимум на одного трудоспособного жителя республики с 2014 по 2019 год в рублях вырос на $40 \%$ - с 5 до 7 тысяч рублей. Среднемесячная зарплата в республике в 2014 2019 годы увеличилась в рублях примерно на 25 \%: с 9 тыс. 900 руб. до 12 тыс. 500 руб. [11].

Доля России в общем внешнеторговом обороте республики составляет более 70 \%. В 2014 2019 годы внешнеторговый оборот находился в пределах \$234-260 млн, при этом наименьший показатель был зафиксирован в 2015 году - 234 млн 751 тыс., наибольший - в 2017 году \$260 млн 596 тыс. В 2019 году, по данным ФТС России, объем внешнеторгового оборота двух стран составил \$253 млн 310 тыс. Экспорт из РФ в Абхазию составил \$190 млн 549 тыс., импорт из Абхазии в РФ - \$62 млн 761 тыс.

С 2014 года сокращается объем помощи по инвестиционной программе содействия социально-экономическому развитию Абхазии. В 2015-2017 годах из бюджета РФ было выделено 9,3 млрд руб. Из них на развитие дорожной сети - 995 млн руб., энергетической отрасли - 733 млн руб., на ремонт и реконструкцию многоквартирных домов и благоустройство территории - 1,8 млрд руб. Инвестпрограмма на 2017-2019 годы составила более 5,8 млрд руб.: на 2017 год - 2,585 млрд, по 1,62 млрд на 2018 и 2019 годы. В рамках утвержденной инвестици- 


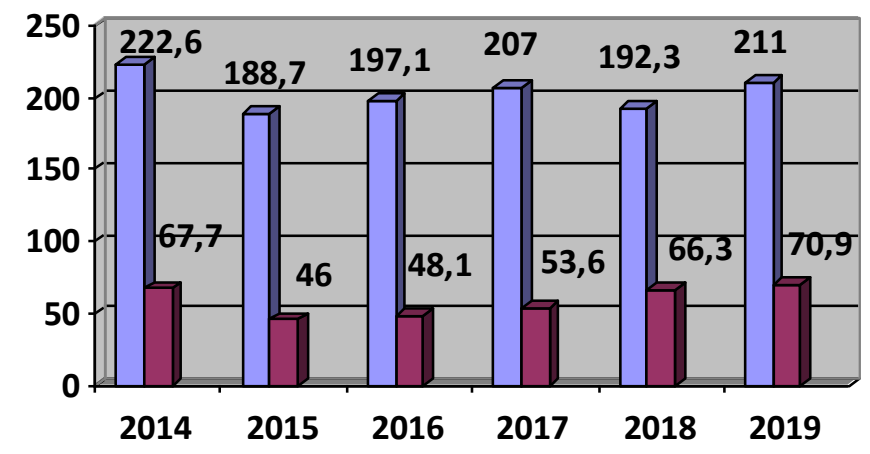

Экспорт $\square$ Импорт $\square$

Puc. 1. Экспорт и импорт Абхазии. Export and import of Abkhasia.

Хотя как экспорт, так и импорт просели в начале исследуемого периода, последние пару лет мы видим наращивание импорта из Абхазии, что является хорошим признаком. Посмотрим на ситуацию более детально.

Товарооборот России и Абхазии за 2014-2019 год, млн долл. Goods

\begin{tabular}{|l|c|c|c|}
\hline \multicolumn{1}{|c|}{ Группа товара } & $\mathbf{2 0 1 4}$ год & $\mathbf{2 0 1 9}$ год & Изменение, \% \\
\hline 01.Продукты животного происхождения & 12,9 & 11,5 & -11 \\
\hline 02. Продукты растительного происхождения & 21,1 & 17,4 & -18 \\
\hline 03. Жиры и масла & 1,0 & 1,1 & +4 \\
\hline 04. Пищевые продукты, напитки, табак & 99,6 & 93,6 & -6 \\
\hline 05. Минеральные продукты & 58,3 & 63,9 & +10 \\
\hline 06. Продукция химической промышленности & 22,0 & 18,7 & -15 \\
\hline 07. Пластмассы, каучук и резина & 5,4 & 6,6 & +22 \\
\hline 08. Изделия из кожи и меха & 0,03 & 0,01 & -55 \\
\hline 09. Древесина и изделия из нее & 5,2 & 3,2 & -38 \\
\hline 10. Книги, бумага, картон & 3,7 & 5,3 & +44 \\
\hline 11. Текстиль & 1,2 & 9,3 & +662 \\
\hline 12. Обувь, головные уборы, зонты и др. & 0,27 & 0,09 & -66 \\
\hline 13. Изделия из камня, керамики и стекла & 5,7 & 10,0 & +75 \\
\hline 14. Драгоценности & 0,14 & 0,1 & -29 \\
\hline 15. Металлы и изделия из них & 21,0 & 12,0 & -43 \\
\hline 16. Машины, оборудование и аппаратура & 15 & 16,5 & +10 \\
\hline 17. Транспорт & 0,97 & 5,2 & +439 \\
\hline 18. Инструменты и аппараты, часы & 2,7 & 1,7 & -38 \\
\hline 19. Оружие и боеприпасы & - & - & - \\
\hline 20. Разные промышленные товары & 7,6 & 5,6 & -27 \\
\hline 21. Произведения искусства и антиквариат & - & - & - \\
\hline 22. Скрытый раздел & 0,15 & 0,6 & +309 \\
\hline & & & \\
\hline
\end{tabular}


Основная доля товарооборота приходится на пищевые и минеральные продукты, химическую промышленность, машины и металлы. В период с 2014 по 2019 год товарооборот слегка снизился за счет уменьшения оборота древесины на $38 \%$, металлов - на $43 \%$, а также промышленных товаров на $27 \%$. Однако следует заметить значительный прирост доли текстиля на $662 \%$, транспорта - на $439 \%$, пластмассы, каучука и резины - на $22 \%$, изделий из камня, керамики и стекла - на 75 \%, а также книг, бумаги и картона - на 44 \%.

Таблица 2

Экспорт из России в Абхазию за 2014-2019 годы, млн долл.

\begin{tabular}{|c|c|c|c|}
\hline Группа товара & 2014 год & 2019 год & Изменение, \% \\
\hline 01.Продукты животного происхождения & 12,8 & 11,4 & -11 \\
\hline 02. Продукты растительного происхождения & 10,7 & 11,0 & +2 \\
\hline 03. Жиры и масла & 1,0 & 1,1 & +4 \\
\hline 04. Пищевые продукты, напитки, табак & 49,8 & 34,4 & -31 \\
\hline 05. Минеральные продукты & 57,4 & 63,6 & +11 \\
\hline 06. Продукция химической промышленности & 22,0 & 18,7 & -15 \\
\hline 07. Пластмассы, каучук и резина & 5,4 & 6,6 & +22 \\
\hline 08. Изделия из кожи и меха & 0,03 & 0,01 & -55 \\
\hline 09. Древесина и изделия из нее & 5,1 & 3,1 & -38 \\
\hline 10. Книги, бумага, картон & 3,7 & 5,3 & +44 \\
\hline 11. Текстиль & 1,2 & 4,5 & +270 \\
\hline 12. Обувь, головные уборы, зонты и др. & 0,27 & 0,09 & -66 \\
\hline 13. Изделия из камня, керамики и стекла & 5,7 & 10,0 & +75 \\
\hline 14. Драгоценности & 0,14 & 0,1 & -29 \\
\hline 15. Металлы и изделия из них & 21,0 & 12,0 & -43 \\
\hline 16. Машины, оборудование и аппаратура & 15,0 & 16,4 & +10 \\
\hline 17. Транспорт & 0,88 & 5,2 & +492 \\
\hline 18. Инструменты и аппараты, часы & 2,7 & 1,7 & -38 \\
\hline 19. Оружие и боеприпасы & - & -- & - \\
\hline 20. Разные промышленные товары & 7,6 & 5,6 & -27 \\
\hline 21. Произведения искусства и антиквариат & - & - & - \\
\hline 22. Скрытый раздел & 0,15 & 0,6 & +309 \\
\hline
\end{tabular}

Заметно уменьшение объемов экспорта российских пищевых продуктов на $31 \%$, древесины - на $38 \%$, металлов - на $43 \%$, промышленных товаров - на $27 \%$. При этом увеличились поставки транспорта на $492 \%$, текстиля - на $270 \%$, книг и бумаги - на 44 \%, изделий из камня и стекла - на $75 \%$, пластмассы и резины - на $22 \%$.

В импорте из Абхазии наблюдается падение в доле продуктов растительного происхождения на 39,1 \%, но при этом также есть и рост поставок пищевых продуктов на 18,9 \% и текстиля.

В целом можно сделать вывод, что внутреннее производство Абхазии развивается достаточно медленно, хотя и наблюдается определенный рост самодостаточности по сравнению с более ранними годами, а также увеличение поставок в страну транспорта, что говорит о развитии транспортной инфраструктуры.

На состоявшейся 12 ноября 2020 года встрече с президентом Республики Абхазия Асланом Бжанией Президент России Владимир Путин заявил, что Россия будет продолжать оставаться главным торговым партнером Абхазии [14]. 
Импорт в Россию из Абхазии за 2014-2019 годы, млн долл.

\begin{tabular}{|c|c|c|c|}
\hline Группа товара & 2014 год & 2019 год & Изменение, \% \\
\hline 01.Продукты животного происхождения & 0,12 & 0,04 & $-66,7$ \\
\hline 02. Продукты растительного происхождения & 10,5 & 6,4 & $-39,1$ \\
\hline 03. Жиры и масла & - & - & - \\
\hline 04. Пищевые продукты, напитки, табак & 49,8 & 59,2 & $+18,9$ \\
\hline 05. Минеральные продукты & 0,9 & 0,33 & $-63,4$ \\
\hline 06. Продукция химической промышленности & 0,218 & - & - \\
\hline 07. Пластмассы, каучук и резина & - & - & - \\
\hline 08. Изделия из кожи и меха & - & - & - \\
\hline 09. Древесина и изделия из нее & 0,12 & 0,11 & $-8,4$ \\
\hline 10. Книги, бумага, картон & - & - & - \\
\hline 11. Текстиль & - & 4,8 & - \\
\hline 12. Обувь, головные уборы, зонты и др. & - & - & - \\
\hline 13. Изделия из камня, керамики и стекла & - & 0,003 & - \\
\hline 14. Драгоценности & - & - & - \\
\hline 15. Металлы и изделия из них & 0,09 & 0,03 & $-66,7$ \\
\hline 16. Машины, оборудование и аппаратура & 0,07 & 0,07 & - \\
\hline 17. Транспорт & 0,09 & 0,01 & $-88,9$ \\
\hline 18. Инструменты и аппараты, часы & - & - & - \\
\hline 19. Оружие и боеприпасы & - & - & - \\
\hline 20. Разные промышленные товары & - & 0,003 & - \\
\hline 21. Произведения искусства и антиквариат & - & - & - \\
\hline 22. Скрытый раздел & - & - & - \\
\hline
\end{tabular}

Абхазия по-прежнему является одним из ключевых поставщиков винодельческой продукции на российский рынок, а также ценной туристической зоной не только для россиян, но и для гостей из других стран.

Республика также предпринимает шаги для развития цифровой составляющей в условиях пандемии, когда поток туристов, являющийся одним из основных источников доходов страны, иссяк в виду закрытия границ.

Министерство экономики Абхазии приступило к внедрению в Абхазии системы электронных государственных сервисов, что является для республики большим шагом вперед. Во многих ведомствах все еще отсутствует корпоративная почта, многие процессы не автоматизированы. Все это замедляет процессы межведомственного содействия, создает проблемы для граждан.

Благодаря новым технологиям коммуникация с органами власти станет проще и лучше Ведомства не будут перенаправлять граждан для решения небольших задач в различные инстанции для получения справок, выписок и прочих документов. Люди смогут меньше посещать государственные учреждения, стоять в очередях и подстраиваться под график служащих [15].

Цифровизация является сложным технологическим процессом, и быстрые перемены в данном направлении невозможны. Власти Абхазии заинтересованы в осуществлении данного проекта в кратчайшие сроки, но есть несколько этапов реализации проектов, которые необходимо пройти, чтобы получить результат. Финансирование первого этапа, а в данном случае речь идет о разработке технического задания и плана мероприятий с определением объема финансирования этапов, уже согласовано с российской стороной, первый этап реализации 
программы предусмотрен. С Россией согласована возможность финансирования данного направления в рамках Инвестиционной программы содействия социально-экономическому развитию Абхазии в 2020-2022 году, и уже одобрено финансирование первого этапа в 2020 году.

Также 21 сентября 2020 года кабинетом министров Абхазии было подписано постановление о мерах регулирования деятельности по добыче криптовалют и отмене действующего с 2018 года решения о запрете на территории республики деятельности по данному виду деятельности с использованием мощностей электроэнергетической системы ИнгурГЭС. Данный запрет был введен в связи с необходимостью приоритетного обеспечения электроснабжения населения Абхазии, социальных и производственных объектов в условиях ограниченных ресурсов электроэнергетической системы. При этом правительство не запрещало завозить оборудование для добычи криптовалюты. За первую половину 2020 года в Абхазию завезли оборудования на 42 миллиона рублей, в 2019 году сумма составила более чем 12 миллионов рублей, несмотря на действующий запрет на добычу [13].

Новое постановление отменило действующий запрет на добычу криптовалюты и обязало всех лиц, занимающихся данной деятельностью, быть зарегистрированными в качестве юридических лиц или индивидуальных предпринимателей, состоять на учете в налоговых органах, органах государственной статистики и государственных внебюджетных фондах.

Выводы. Подводя итог, можно выделить три ограничителя экономического развития Абхазии.

Во-первых, ощущается недостаток госрегулирования, отсутствия универсального правового поля. Результатом является развитие теневой экономики.

Во-вторых, ограничения со стороны инфраструктуры, которая была создана в Абхазии еще во времена Советского Союза и с тех пор не обновлялась, став малопригодной для современных потребностей и развития экономики. Инфраструктурный уклад нового типа уже существует не только в России, но и в Грузии и Армении, и включает в себя газ, новые ГЭС, аэропорты, развитую цифровизацию. В Абхазии отсутствует газ, нет независимой энергосистемы, транспортных узлов, мало дорог, границы закрыты.

Наконец, естественные ограничители: вызванная прошедшими военными действиями депопуляция, отсутствие внутреннего рынка. Из-за неспокойной внутренней обстановки и слабой защищенности бизнеса инвесторы теряют интерес к данному региону [16].

Еще десять лет назад у Абхазии была возможность выстраивания экономических отношений, ориентированных на российский рынок, сегодня же дальнейшее развитие Абхазии труд-

Литература

1. Абхазии все тяжелее бороться за туриста. [Электронный ресурс]. Режим доступа: https:// ria.ru/20180805/1525963428.html, свободный. - Загл. с экрана.

2. Вардомский Л. Б. О повороте Российской экономики на Восток // Проблемы теории и практики управления. - 2016. - № 7. - С. 21-29.

3. Вардомский Л. Б. Об Азиатском векторе развития России // Всероссийский экономический журнал ЭКО. - 2015.

4. Вардомский Л. Б. Об усилении азиатского фактора трансформации экономического пространства России // Мир перемен. - 2015. - № 2. - С. 114-128.

5. Вардомский Л. Б. Постсоветский интеграчионный проект: что хотели и что получили // Мир перемен. - 2016. - № 3. - С. 8-23.

6. Вардомский Л. Б. Россия и постсоветская регионализация // Россия и современный мир. - 2009. - № 3 (64). - C. 83-107.

7. Вардомский Л. Б. Социально-экономическое развитие постсоветских стран: итоги двадиатилетия: монография. - М.: ИЭ РАН, 2012. - 400 c.

8. Вардомский Л. Б., Пылин А. Г. География внешнеторговых связей государств общего соседства ЕС и России в 2000-2014 годах // Россия и современный мир. - 2015. - № 2 (87). - С. 60-80.

9. Гринберг Р., Вардомский Л. Десятилетие эволючии и перспективы структурирования постсоветского экономического пространства // Российский экономический журнал. - 2001. - № 8. - C. 55-67.

10. История Абхазии. [Электронный ресурс]. Режим доступа: URL:: https:// ria.ru/20120814/722748974.html, свободный. - Загл. с экрана.

11. Итоги деятельности Рауля Хаджимбы на посту президента Абхазии за шесть лет. [Электронный pecypc]. Режим достуnа: https://tass.ru/info/7510961, свободный. - Загл. с экрана.

12. Новости Абхазии - Спутник. [Электронный ресурс]. Режим доступа: https://sputnik-abkhazia.ru/ interview/20191025/1028682337/Ugroza-natsionalnoy-bezopasnosti-TsSI-otsenil-sostoyanie-ekonomiki-

Abkhazii.html, свободный. - Загл. с экрана. 
13. Новости Абхазии - Спутник. [Электронный ресурс]. Режим доступа: https://sputnik-abkhazia.ru/ Abkhazia/20201110/1031259389/Minekonomiki-Abkhazii-vklyuchilo-v-reestr-65-ferm-po-dobyche-

kriptovalyut.html, свободньй. - Загл. с экрана.

14. Посольство республики Абхазии в Российской Федерации. [Электронный ресурс]. Режим доступа: http://www.emb-abkhazia.ru/respublika_abhaziya/histori/chrono6/, свободный. - Загл. с экрана.

15. Россия остается для Абхазии «п̄артнёром номер один». [Электронный ресурс]. Режим доступа: https://regnum.ru/news/polit/3113802.html, свободный. - Загл. с экрана.

16. Экономики Абхазии не будет без кардинальных изменений. [Электронный ресурс]. Режим доступа: https://eadaily.com/ru/news/2019/04/06/anton-krivenyuk-ekonomiki-abhazii-ne-budet-bez-kardinalnyhizmenепіу, свободный. - Загл. с экрана.

17. Экспорт и импорт России по товарам и странам. [Электронный ресурс]. Режим доступа: http://ru -stat.com, свободный. - Загл. с экрана.

References:

1. Abhazii vse tyazhelee borot'sya za turista. [Elektronnyj resurs]. Rezhim dostupa: https:// ria.ru/20180805/1525963428.html, svobodnyj. - Zagl. s ekrana.

2. Vardomskij L. B. O povorote Rossijskoj ekonomiki na Vostok // Problemy teorii i praktiki upravleniya. 2016. - № 7. - S. 21-29.

3. Vardomskij L. B. Ob Aziatskom vektore razvitiya Rossii // Vserossijskij ekonomicheskij zhurnal EKO. 2015.

4. Vardomskij L. B. Ob usilenii aziatskogo faktora transformacii ekonomicheskogo prostranstva Rossii // Mir peremen. - 2015. - № 2. - S. 114-128.

5. Vardomskij L. B. Postsovetskij integracionnyj proekt: chto hoteli i chto poluchili // Mir peremen. - 2016. № 3. - S. 8-23.

6. Vardomskij L. B. Rossiya i postsovetskaya regionalizaciya // Rossiya i sovremennyj mir. - 2009. - № 3 (64). - S. 83-107.

7. Vardomskij L. B. Social'no-ekonomicheskoe razvitie postsovetskih stran: itogi dvadcatiletiya: monografiya. - M.: IE RAN, 2012. - 400 s.

8. Vardomskij L. B., Pylin A. G. Geografiya vneshnetorgovyh svyazej gosudarstv obshchego sosedstva ES $i$ Rossii v 2000-2014 godah // Rossiya i sovremennyj mir. -2015. - № 2 (87). - S. 60-80.

9. Grinberg R., Vardomskij L. Desyatiletie evolyucii i perspektivy strukturirovaniya postsovetskogo ekonomicheskogo prostranstva // Rossijskij ekonomicheskij zhurnal. - 2001. - № 8. - S. 55-67.

10. Istoriya Abhazii. [Elektronnyj resurs]. Rezhim dostupa: URL:: https://ria.ru/20120814/722748974.html, svobodnyj. - Zagl. s ekrana.

11. Itogi deyatel'nosti Raulya Hadzhimby na postu prezidenta Abhazii za shest' let. [Elektronnyj resurs]. Rezhim dostupa: https://tass.ru/info/7510961, svobodnyj. - Zagl. s ekrana.

12. Novosti Abhazii - Sputnik. [Elektronnyj resurs]. Rezhim dostupa: https://sputnik-abkhazia.ru/ interview/20191025/1028682337/Ugroza-natsionalnoy-bezopasnosti-TsSI-otsenil-sostoyanie-ekonomiki-

Abkhazii.html, svobodnyj. - Zagl. s ekrana.

13. Novosti Abhazii - Sputnik. [Elektronnyj resurs]. Rezhim dostupa: https://sputnik-abkhazia.ru/ Abkhazia/20201110/1031259389/Minekonomiki-Abkhazii-vklyuchilo-v-reestr-65-ferm-po-dobyche-

kriptovalyut.html, svobodnyj. - Zagl. s ekrana.

14. Posol'stvo respubliki Abhazii v Rossijskoj Federacii. [Elektronnyj resurs]. Rezhim dostupa: http:// www.emb-abkhazia.ru/respublika_abhaziya/histori/chrono6/, svobodnyj. - Zagl. s ekrana.

15. Rossiya ostaetsya dlya Abhazii "partnyorom nomer odin». [Elektronnyj resurs]. Rezhim dostupa: https:// regnum.ru/news/polit/3113802.html, svobodnyj. - Zagl. s ekrana.

16. Ekonomiki Abhazii ne budet bez kardinal'nyh izmenenij. [Elektronnyj resurs]. Rezhim dostupa: https:// eadaily.com/ru/news/2019/04/06/anton-krivenyuk-ekonomiki-abhazii-ne-budet-bez-kardinalnyh-izmeneniy, svobodnyj. - Zagl. s ekrana.

17. Eksport i import Rossii po tovaram i stranam. [Elektronnyj resurs]. Rezhim dostupa: http://ru-stat.com, svobodnyj. - Zagl. s ekrana. 